the side who would abolish the risk by early extirpation of the infective element." These words seem to mean that, even if a surgeon considers that the risk of general infection is small, he should still endeavour to abolish it by early excision. Nothing, I think, could show more clearly what a trivial proceeding the removal of the large joints of the body is in the eyes of some operators of the present day.

Lastly, Mr. Croft says it was a noteworthy fact that in my lectures I said nothing about arthrectomy, and adds that there may be more than one good reason for the omission. My reasons were the following:-1. I was speaking mainly of the hip, a joint for which I believe arthrectomy is not considered, even by its warmest advocates, to be appropriate. 2 . I was noticing the views of Mr. Croft and Mr. Barker as to early excision, and neither of these two surgeons has, so far as I know shown or published any results of arthrectomy. 3. I had seen only a few cases in which the proceeding had been adopted, and these, while they had not made a favourable impression on my mind, were yet too few to justify any strong opinion against the operation. I will now, however, state my belief that arthrectomy is not destined to furnish a satisfactory result except in a very limited number of cases. My anticipation is that as the surgery of the joints advances, arthrectomy and excision will alike fall more and more into disuse.

There is a fact which deserves to be especially noticed in regard to the employment of excision in the treatment of tuberculosis of the joints. This is that in the well-to-do the operation is almost unknown, although tuberculosis is certainly by no means rare. Such a fact clearly shows that means exist by which the operation can be avoided : that in other words the operation is not essential. But it shows also that those in whom excision could be performed under the most favourable conditions are those who next to never avail themselves of the adrantages which it has, in the view of its advocates, to offer. At the present day the well-to-do freely accept the advances which surgery has lately made. When ovarian disease is present they submit to ovariotomy, for there is no alternative, and besides, they know that they can trust the remedy that is offered to them. In the same way they submit to lithotrity, colotomy, the removal of tumours, and many other grave operations. But, as to excision, they and their advisers almost invariably reject it, for they learn, first, that the results are unsatisfactory, and, secondly, that there are alternative and more promising means to be adopted. Of course it may be urged that the rich are enabled by their resources to avoid methods of treatment which are the best that can be employed for poor patients. There are many cases in which this is true. But this is not the ground on which excision is at present advocated. Excision is now advocated upon grounds, many of which are either purely pathological or purely surgical : that tuberculosis should be regarded in the lioht of a nialignant disease, and be treated accordingly; that the limb secured by excision is only a trifle shorter than that which is left after cure without operation; thst sequestra are present which require removal, \&c. Srach grounds as these apply equally in the case of the wellto-do as in the case of the poor, and the first of them would render it imperative to excise every local development of tubercle-wherever it could be got at, and as soon as caseation was suspected-in the rich as well as in the poor. Tu such a point, indeed, have the arguments in favour of excision been carried by some of its advocates, that the possibility of curing tubercular joint disease by means short of operation is almost entirely ignored.

NEW SCAVENCER DEPOT, UPPER THAMES-STREET. Mr. Deputy Green, in the presence of the Streets Committee and other members of the City Commissioners of Sewers, formally laid the foundation-stone of a new Scavengers' Depot, in course of erection by the Commissioners of Sewers in Upper Thames-street. The chairman stated that the committee looked forward to a great improvement in the cleansing of the streets. The depôts were of the greatest use, not for a deposit of any refuse, but for the assembling of men and boys, who there could take their meals by night or day. About 100 men and youths were employed on the work. It is also intended to provide on a contiguous site a building which will contain mess-room, workshop, kitchen, and offices, superintendent's dwelling-rooms, and foreman's house.
THE

\section{OPERATIVE TREATMENT OF DISLOCATIONS IRREDUCIBLE BY ORDINARY MEANS.}

BY A. W. MAYO ROBSON, F.R.C.S.,

HONORARY SURGEON TO THE I.EEDS GENIEIAL INIIRMARY, CONSULTING SURGEON TO THE BATLEY IIOSPITAL, LECTURER ON PRACTICAL

SURGERY IN THE YORTSHIRE COLLFGE, AND LXAMINEI IN THE VICTORIA UNIVERSITY.

IN this paper are given notes of cases in which, after ordinary means of reduction had failed, joints were ex. plored through an incision, and either reduced or otherwise treated. In contrast with these are quoted cases where operation had been declined by the patient or not advised by the surgeon.

CASE 1. Irreducible dislocation of the elbow backwards, seen four weeks after the injury; operation; cure.-Wm.T.W-., aged eleven, was admitted to the Leeds Infirmary on Sept.7th, 1886, with a well-marked dislocation of the left elbow, both bones being displaced backwards. No fracture could be made out. The arm was fixed at an angle of $130^{\circ}$, and the movements were very limited, not exceeding $10^{\circ}$. The injury had been caused four weeks previously by a fall from a pony. On Sept. 10th the patient was put under ether and reduction attempted. Some increased mobility was obtained, but the dislocation could not be reduced. A vertical incision, four inches in length, was then made over the elbow-joint; the triceps tendon was divided, and the joint opened. It was then seen that the coro. noid process was broken off and fractured into two parts, one being attached to the tendon of the brachialis anticus, and the other (a smaller fragment) to the stump of the coronoid process; this latter was subsequently removed. The external lateral ligament was ruptured and displaced, and through the rent in the ligament the head of the radius was thrust, the displaced ligament being placed between the head of the radius and the capitellum, thus preventing reduction. On division of the ligament, the dis. location was reduced, the parts slipping easily into position. The joint was well irrigated with perchloride of mereury solution, the triceps tendon stitched with four catgut sutures, and the wound closed, a drainage-tube being inserted. The arm was placed on an internal rectangular splint, and the wound dressed with gauze and salicylic silk. The wound healed by first intention, and the patient was discharged on Oct. 5 th. Two months later the patient had a good, freely movable, and useful elbow-joint.

CASE 2. Old irreducible dislocation of the elbow-joint backwards, seen five morths after the injury; excision.Lily W-, aged twenty-two, was admitted on Oct. 30th, 1889 , on account of a dislocation of her left elbow back. wards, which had been caused by her being thrown out of a trap five months previously. No attempt at reduction had been made. The elbow was fixed at an oblique angle, the movements being limited to $12^{\circ}$, and the patient being unable to feed herself with the left hand. On the 3 lst the patient was anesthetised, and reduction attempted by manipulation and by pulleys, but without avail. An incision was therefore made over the posterior part of the joint, when the capitellum was found to have been broken off and fixed in the coronoid fossa by means of callus. The arm could not be brought into a good position until the lower end of the humerus had been removed, after which this was easily effected. The edges of the wound were then brought together, and the arm was fixed on an internal rectangular splint. The patient was discharged at the beginning of December with the wound quite healed, and when seen in February the movements of the elbow seemed to be extremely good, and the patient said that her arm was as useful as it had ever been.

CASE 3 Dislocation of both bones of right elbow bachwards.-A. B-, a schoolboy aged fourteen, was brought to see me six weeks after an injury to his right elbow, caused by a fall when playing football. I found a dislocation of both bones backwards, and tried to effect reduction under an anæsthetic, but failed. Further operation was advised, but declined, and when I last heard of him, a year after the injury and about three months ago, he was unable to feed himself with his right arm, and the movements of the elbow were extremely limited.

CAss 4. A case of supra-coracoid dislocation of the 
shoulder, seen six weeks eifter the accident. - In January, 1889, a youth aged sixteen was brought to the infirmary with a supra-coracoid dislocation of the right shoulder. After consultation, on Feb. 2nd the patient was fully anesthetised, and reduction was attempted by manipulation and by pulleys, but without success. The joint was therefore exposed by a vertical incision of four inches and a half, when it was discovered that, in addition to the dislocation of the head of the humerus, there was a longitudinal fracture separating the great tuberosity from the shaft, and extending down the bone for some distance beyond the line of incision. Reduction could not be effected on account of the glenoid fossa being filled with callus and plastic material thrown out around the fracture. The wound was closed and drained, and was quite healed on the ninth day. On March 17 th, when seen as an outpatient, he had a good range of movement in the arm, and intended resuming his work in a short time.

CASE 5. Dorsal dislocation of right hip, seen ten weeks after the injury; excision of head of femur.-John Saged thirty-five, residing at Altofts, was admitted on March 19th, 1889, with the history that he had been kicked by $a$ horse on the inner side of the right thigh ten weeks previously. Dislocation of the femur was diagnosed, and was said to have been reduced, but on admission the usual signs of dislocation on the dorsum ilii were found. On March 21st the patient was anæsthetised and an attempt made to reduce the dislocation by manipulation, but without effect. On March 28th, the patient was put under ether, and an effort made to reduce it by means of pulleys, but without success. On April 1Ith, after consultation, a curved incision of about three inches in length was made over the head of the bone; all tight bands and everything which appeared to prevent reduction were divided, but re duction could not be made, as the acetabulum was found to be filled up with callus, so that it was almost level with the crest of the ilium. The head of the bone was therefore excised and the limb brought into fair position. The operation was performed antiseptically, and a drainage-tube was used. Bryant's splint was then applied. The wound was dressed on the night of the operation, and not again for some days. It pursued an aseptic course and healed kindly. $\mathrm{He}$ was allowed to go home on a Thomas' splint and crutches on May 22nd. On Dec. 12th (nine months after the operation) the following description was given me by my house surgeon, Mr. Sellers: The right gluteal region appears flatter and wider than the left, the distance between the middle line and the great trochanter being $7 \frac{1}{4}$ in. on the right and 6 in. on the left; the superior border of the right great trochanter appears about $1 \frac{3}{4}$ in. above that of the left there is $1 \frac{3}{4}$ in. shortening between the anterior superior spine of the ilium and the inferior border of the patella. There is a semilunar cicatrix extending from the right ischial tuberosity to the upper border of the right great trochanter. The thigh can be flexed on the abdomen painlessly to about $15^{\circ}$ beyond the vertical ; it can be adducted, abducted, and circumducted to the full normal extent, and can be extended fully. The foot points forward, and there is no eversion or inversion of the limb. The patient can walk with a raised shoe and without a stick for a little way, but wich the aid of a stick he can walk a considerable distance.

CASE 6. Irreducible thyroid dislocation of hip, scen eight weels a ter the injury.-L. S__, aged fifty-three, was admitted on June 27th, 1888, with all the signs of thyroid dislocation of the right hip-joint, due to an accident eight weeks previously. On July 5 th the patient was anresthetised, and reduction attempted both by manipulation and by means of pulleys, but without success, and he returned home on July 9th, unrelieved. When seen six months afterwards he walked with considerable difficulty, even with the aid of two sticks.

C.SE 7. Dislocation of the left hip.-In $1888 \mathrm{I}$ was asked to see a gentleman in a neighbouring county, whose horse had fallen on him in the hunting field six weeks previously. There was so much swelling at the time of the injury that the medical man who saw him did not make a diagnosis, and only suspected that matters were not going on well a few days before I was sent for. I found a sciatic dislocation of the left hip, which resisted repeated attempts to reduce it by manipulation and by means of pulleys, although the patient was fully anresthetised. Operation was suggested, but declined; and although the patient, when heard of a year after, could walk with the aid of two sticks, he was unable to ride, and suffered great inconvenience in locomo. tion.
Cass: 8. Irreducible dislocation of finger, scen three wecks after the accident; operation; reduction.-A. C- was admitted on Nov, 2nd, 1888, on account of a dislocation of the first phalanx of the index-finger backward, due to a fall three weeks previously. Reduction was attempted under an ansesthetic, but failed. An incision was therefore made on the outer side of the finger, and the joint was opened, when the anterior fibro-cartilage was found displaced be. tween the bones, where it was held by the external lateral ligament. On division of the ligament, the fibro-cartilage was withdrawn from the joint by a blunt hook, and the dislocation was then easily reduced. The wound healed by first intention, and when the patient was seen a month afterwards the joint was found to be perfect in all its move. ments. Several similar instances might be given, but this will suffice.

CASE 9. Dislocation of the first phalanx of the little finger.-Mrs. P —, aged forty, fell heavily forward and sustained a dislocation of the first phalanx of the little finger. When I saw it, eight weeks after the injury, I was unable to effect reduction, and the patient declined operation. The joint is at present (six months after the accident) fixed, and the finger is useless and always in the way.

Remarks. - I would draw attention to the several conditions which prevented reduction. In Case 1 the head of the radius had slipped through a rent in the external lateral ligament, where it was embraced like a button in a buttonhole. In Case 2 a fractured capitellum was fixed by callus in the coronoid fossa, and the removal of the lower end of the humerus seemed to be necessary in order that a movable joint might be made. In Case 8 the anterior fibro-cartilage had slipped between the ends of the bones, which could not be reduced until the fibro-cartilage had been drawn out of the way. In Case 4 a split fracture with the formation of callus prevented reduction, but as a false joint was in process of formation, and as there seemed to be a likelihood of fair movement, the head of the bone was not further interfered with. In Case 5, much to my surprise, the acetabulum was filled up with callus, and the rim was almost level with the ilium; the head of the femur was therefore removed, and the limb could then be brought into fair position. I have introduced a few instances of old dislocations out of many I have seen, in which operation was declined, or was not recommended, in order to show how unsatisfactory these cases are if left permanently unreduced, as compared with those in which further operative treatment has been carried out. In conclusion, as I have never seen any harm, but always benefit, to result from the treatment suggested, I feel justified in advocating a resort to operation in all cases of irreducible dislocation when the general condition of the patient is such as to warrant the belief that he will bear an operation.

Leeds.

ON THE

USE OF THE DENTAL TREPHINE IN THE TREATMENT OF SPURS AND DEVIATIONS OF THE NASAL SEPTUM AND SYNECHI $\&$ OF THE NASAL FOSS E.

BY ADOLF BRONNER, M.D.,

SURGEON TO THE BRADFOILD LYE AND EAR HOSPITAL.

$\mathrm{ON}_{\mathrm{N}}$ examining the interior of the nares by anterior and posterior rhinoscopy we are struck by the large number of cases in which the septum narium is bent or thickened. Morell Mackenzie examined 2152 skulls, and found that in 1657 cases, or 77 per cent., there was a more or less unsymmetrical position of the septum. Zuckerkandl ${ }^{1}$ found that in 370 skulls the septum was symmetrical in 123 cases, unsym. metrical in 140 , and irregularly thickened in 107 . He says that the septum was always symmetrical in skulls of children under seven years of age. Loewenberg ${ }^{2}$ found that the septum was perfectly straight only in about 14 per cent. of the cases he had examined.

The great importance of these deviations and hypertrophies, commonly called spurs, is that they in many cases

1 Normale und Pathologische Anatomie der Nasenhohle, 1882. Anatomische Unter'suchungen uber die Verbiegung der Nasenscheidewand (Zeitschrift fïr Ohrenheilkunde, xiii,, p. 17).

$$
\text { L } 2
$$

